\title{
Karyotypic characterization of Ramphastidae (Piciformes, Aves)
}

\author{
Márcio Siqueira Castro ${ }^{1}$, Shirlei M. Recco-Pimentel ${ }^{1}$ and Guaracy Tadeu Rocha ${ }^{2}$ \\ ${ }^{l}$ Departamento de Biologia Celular, Instituto de Biologia, Universidade Estadual de Campinas, Campinas, \\ SP, Brazil. \\ ${ }^{2}$ Departamento de Genética, Instituto de Biociências, Universidade Estadual Paulista, Botucatu, SP, Brazil.
}

\begin{abstract}
The karyotypes of nine species of the family Ramphastidae were determined and compared with that of the toco toucan (Ramphastos toco), the only ramphastid karyotype so far reported in the literature. Differences in the morphology of the largest chromosomes allowed to identify three karyotype groups. The first group included the species R. toco, Baillonius bailloni, Pteroglossus castanotis, P. aracari and Selenidera maculirostris, in which only the first pair of chromosomes was metacentric. The second group included four Ramphastos species ( $R$. dicolorus, $R$. ariel, $R$. vitellinus, $R$. tucanus cuvieri) with two pairs of metacentric macrochromosomes (the first and the seventh). The third group was represented by a single species, $A$. laminirostris, in which all the autosomal chromosomes were telocentric. All of the species had subtelocentric $Z$ chromosomes, similar in size to homologues of the first pair. Sex chromosome W was a small chromosome. The chromosome number ranged from $2 \mathrm{n}=62$ in $P$. aracari to 114 in $R$. toco. The cytotaxonomic relationships among toucan species are discussed, based on chromosome analysis.
\end{abstract}

Key words: karyotypes, Rhamphastidae, toucans.

Received: March 5, 2002; accepted: May 27, 2002.

\section{Introduction}

The family Ramphastidae (Piciformes - Aves) is composed of toucans, the most typical neotropical birds (Haffer, 1974), endowed with extraordinary characteristics and exuberant colors (Sick, 1997). Fifty-five species were described in this family, 27 of which are found in Brazil. The only one whose karyotype had been described so far is Ramphastos toco. The family Ramphastidae comprises two subfamilies: Capitonidae, with three genera and 14 species, and Ramphastinae, with six genera and 41 species (Sibley, 1996).

The chromosome number of $R$. toco is $2 \mathrm{n}=106$ (Takagi and Sasaki, 1980). Sex chromosome Z is subtelocentric and equivalent in size to the first chromosome pair, which is metacentric. The remaining chromosomes are telocentric. Sex chromosome $\mathrm{W}$ is a microchromosome, not identified by these authors. Nogueira and Goldshimidt (1994) analyzed six specimens of $R$. toco, and reported $2 n=80$ chromosomes. Cytogenetic data are important for the characterization of each species, and can help to establish their karyotype evolution. In this work, we examined the karyotypes of ten Ramphastidae species, in order to

Send correspondence to Shirlei M. Recco Pimentel. Departamento de Biologia Celular, IB, UNICAMP, 13084-971 Campinas, SP, Brazil. E-mail: shirlei@unicamp.br. assess chromosomal evolution and cytotaxonomic relationships in this family.

\section{Materials and Methods}

Ten Ramphastidae species of the subfamily Ramphastinae (Piciformes, Aves) were cytogenetically analyzed: Ramphastos toco Mueller, 1776 (25 males, 26 females), $R$. dicolorus Linnaeus, 1776 (9 males, 11 females), $R$. ariel Vigors, 1826 (2 males, 7 females), $R$. vitellinus Reiser, 1905 (2 females), R. tucanus cuvieri Wagler, 1827 (1 male), Baillonius bailloni Vieillot, 1819 (2 males, 5 females), Pteroglossus castanotis Gould, 1834 (1 male, 3 females), P. aracari Linnaeus, 1758 (2 males), Selenidera maculirostris Lichtenstein, 1823 (4 males, 3 females), and Andigena laminirostris Gould, 1850 (2 males). All specimens showed adult characteristics, and were maintained by ecological parks, zoological gardens or with private bird breeders in the State of São Paulo.

The chromosome preparations were obtained using the dermal pulp tissue of growing feathers (approximately 15-30 days growth). This tissue was macerated and incubated in culture medium (RPMI) for $30 \mathrm{~min}$. with $0.016 \%$ colchicine, at room temperature. The cell suspension was then centrifuged at $1000 \mathrm{~g}$ for $10 \mathrm{~min}$, and the pellet resuspended in $10 \mathrm{~mL}$ of $0.075 \mathrm{M} \mathrm{KCl}$ (hypotonic solution) for $30 \mathrm{~min}$, after which the cells were fixed in a $3: 1(\mathrm{v} / \mathrm{v})$ 
methanol:acetic acid solution. Following two rinses with fixative, the suspension was spotted onto slides. These steps were done in the field. The slides were subsequently stained with $10 \%$ Giemsa solution (in phosphate buffer, $\mathrm{pH}$ 6.8 ), and examined at a 100x magnification.

The sex chromosomes were determined using the best metaphase plates, and the maximum chromosome number found was considered as being the diploid number of the respective species. The description of chromosome morphology was based on that of Levan et al. (1964).

\section{Results}

In this study on toucan species, sex was determined by cytogenetic analysis. The female specimens of the ten species had sex chromosomes (ZW) that differed in size and/or morphology. Based on the morphology of the largest chromosomes, three groups of species were identified in this family.

\section{Group I}

\section{Ramphastos toco, Baillonius bailloni, Pteroglossus} castanotis, $P$. aracari and Selenidera maculirostris

All 51 specimens of $R$. toco had the same karyotype as described by Takagi and Sasaki (1980). The chromosomes of the first pair were the only metacentric ones, their size being twice the size of the second pair (Figure 1: $A_{1}$ and $A_{2}$ - male; $A_{3}$ and $A_{4}$ - female). The $Z$ chromosome was subtelocentric and was similar in size to the autosomes of the first pair. The remaining chromosomes were telocentric and progressively decreasing in size. It was not possible to identify the homologues, nor the w chromosome. This species had a diploid number of 114 chromosomes.

The same karyotype pattern was found in Baillonius bailloni (Figure 1F), Pteroglossus castanotis (Figure 1G), $P$. aracari (Figure 1H), and Selenidera maculirostris (Figure 21I), but they differed in their diploid chromosome numbers $(2 \mathrm{n}=92 ; 2 \mathrm{n}=86 ; 2 \mathrm{n}=62$; and $2 \mathrm{n}=98$, respectively).

\section{Group II}

Ramphastos dicolorus, $R$. ariel, $R$. vitellinus and $R$. tucanus cuvieri

The analysis of metaphases from these species showed chromosome groups similar to those observed in $R$. toco. A pair of large metacentric chromosomes was identified as the first pair. The $\mathrm{Z}$ chromosome was subtelocentric and equivalent in size to the first pair. Among the telocentric chromosomes, there was one metacentric pair that corresponded in size to the seventh pair of the previous group. The $\mathrm{W}$ chromosome was impossible to identify. The diploid chromosome numbers were: $2 \mathrm{n}=98$ for $R$. dicolorus (Figure 1B), 2n=106 for $R$. ariel (Figure 1C),
$2 \mathrm{n}=102$ for $R$. vitellinus (Figure 1D), and $2 \mathrm{n}=88$ for $R$. tucanus cuvieri (Figure 1E).

\section{Group III}

\section{Andigena laminirostris}

The only species included in this group, Andigena laminirostris (Figure 1J), does not inhabit Brazil, but occurs in Ecuador (Gould, 1992). Two males of this species were included in this analysis, to compare their karyotype with that of the various Brazilian species. A. laminirostris had $2 \mathrm{n}=108$ chromosomes, one of them being an unusual chromosome that corresponded in size and morphology to the $\mathrm{Z}$ chromosome described above. The second chromosome pair was $2 / 3$ the size of the first pair. The second pair and all the other chromosomes were telocentric and gradually decreasing in size.

The two specimens of $A$. laminirostris were considered to be males, because no heteromorphic chromosome pair, corresponding to ZW, was found. They were both subsequently sexed as males by DNA analysis. The unusually large pair of chromosomes found in A. laminirostris was similar in size and morphology to the $\mathrm{Z}$ sex chromosomes of the other Ramphastidae species , and was therefore considered to represent the $\mathrm{Z}$ chromosomes. This will only be confirmed after karyotype analysis of females and identification of the ZW sex chromosome pair.

\section{Discussion}

Based on our chromosome analysis, we worked out the following hypothesis: $R$. toco may descend from a more ancient branch, and the metacentric seventh pair may be the result of a single translocation that occurred late in the origin of the $R$. toco branch, but early enough to be present in the ancestry of $R$. dicolorus, $R$. tucanus, $R$. vitellinus and $R$. ariel.

The metacentric chromosomes identified as the seventh pair were good marker chromosomes, because of their similar size and morphology in the various Ramphastos species, except for $R$. toco. Independent translocations involving different chromosomes are unusual events. The presence of these chromosomes in different species suggests that they were inherited via a common ancestor. This interpretation is even more consistent when the diploid chromosome number of different species is considered.

According to Takagi and Sasaki (1980), the ancestors of many orders of birds had karyotypes with many chromosomes, all of them telocentric, except for the first pair. This same ancestral pattern was reported by Beltermann and De Boer (1984), after their analysis of the karyotypes of various species from 15 orders, and by Rodionov (1997), after examining the published karyotypes of almost 800 avian species. $R$. toco and A. laminirostris have probably main- 
$A_{1}$

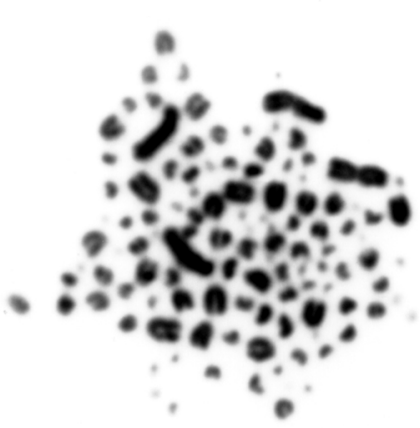

$A_{3}$

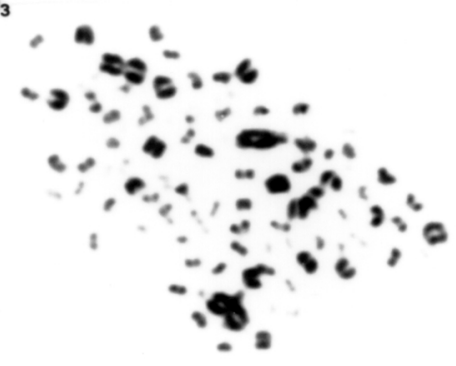

$A_{2}$

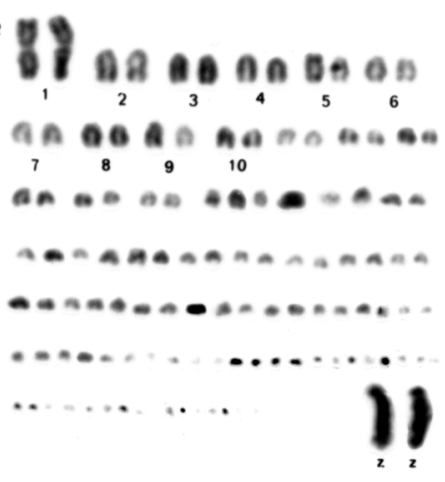

$A_{4} 88$ m

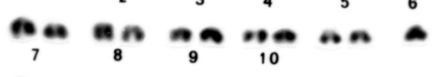

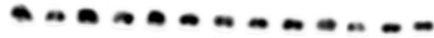
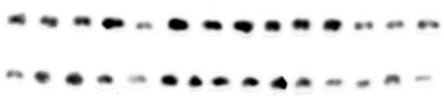

$\cdots, \ldots \ldots \ldots, \theta_{z}$

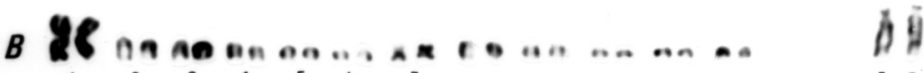

C $8 \mathbf{8}$ n

D

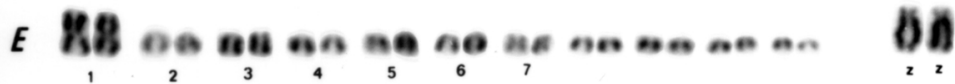

F It a

G 8 8̊ n

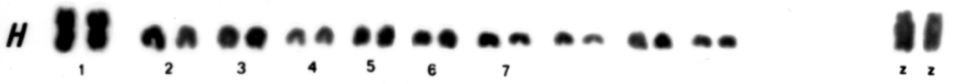

I 88 •

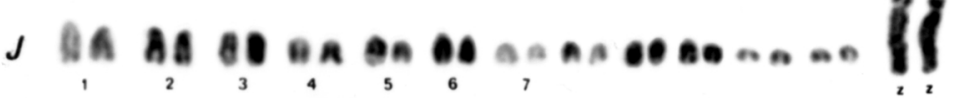

Figure 1 - $\mathrm{A}_{1}$. Mitotic metaphase of $R$. toco (male), $\mathrm{A}_{2}$. karyotype of $R$. toco (male), $\mathrm{A}_{3}$. Mitotic metaphase of $R$. toco (female), $\mathrm{A}_{4}$. Karyotype of $R$. toco (female). Partial karyotypes of B. Ramphastos dicolorus, C. R. ariel, D. R. vitellinus, E. R. tucanus cuvieri, F. Baillonius bailloni, G. Pteroglossus castanotis, H. P. aracari, I. Selenidera maculirostris and J. Andigena laminirostris.

tained the ancestral karyotype pattern of these genera from 800,000 years ago.

During the differentiation of more recent branches, in-tandem translocations may have reduced the diploid chromosome numbers of current species. This would explain why $R$. tucanus, a representative of a more recent lineage than $R$. toco, had the lowest chromosome number $(2 \mathrm{n}=88)$. Centric fusion after differentiation of the $R$. toco 
lineage would have given rise to the metacentric seventh chromosome pair of other Ramphastos species.

In-tandem translocations may have occurred after the separation of $R$. toco and $R$. tucanus, and were probably more recently intensified in $R$. tucanus $(2 \mathrm{n}=88)$, but less intensive in $R$. dicolorus $(2 \mathrm{n}=98), R$. ariel $(2 \mathrm{n}=106)$ and $R$. vitellinus $(2 \mathrm{n}=102)$. In Selenidera and Baillonius, $2 \mathrm{n}$ is 98 and 92, respectively, whereas the diploid number in $P$. aracari is $2 \mathrm{n}=62$, and in $P$. castanotis, $2 \mathrm{n}=86$. In-tandem translocations could account for this reduction of the chromosome number in Pteroglossus species, although, as pointed out by Rodionov (1997), the rates of karyotypical change differ among phylogenetic branches of birds.

In nine of the species studied here, the first autosome pair was metacentric and was double the size of the second pair. In A. laminirostris, all the autosomes were telocentric and gradually decreasing in size. In the karyotypical patterns proposed by Takagi and Sasaki (1980) and Beltermann and De Boer (1984) for the ancestors of many avian orders, the first and second pairs are metacentric and submetacentric. According to Takagi and Sasaki (1980), centric fission in one of these pairs would culminate in the karyotype observed in R. toco. According to these authors, in certain species of some orders (Strigiformes, Gruiformes), centric fission has occurred in both chromosome pairs, resulting in telocentric chromosomes. Such a series of events (centric fission of metacentric chromosomes) could explain the karyotype of A. laminirostris. However, as pointed out by Beltermann and De Boer (1984), the confirmation of this hypothesis would require chromosome banding analysis, to verify the homology among the largest chromosomes of different species, families and orders.

All species examined here had subtelocentric $Z$ chromosomes, which were similar in size to the first pair. The sex chromosome $\mathrm{W}$ was a microchromosome not observed in females, and only C-banding patterns could identify this small chromosome in these species. This pattern was not observed in other families of the order Piciformes. Shields et al. (1982) reported that, in the family Picidae, the Z chromosome may be subtelocentric or metacentric, whereas chromosome W can be small and telocentric (Dendrocopus major) or submetacentric, or one of the largest in the karyotype (D. minor). Similar variation in sex chromosome size and morphology occurs in Picoides, Colaptes and Sphirapicus. Two species of the family Megalaimidae, Megalaima haemacephala (Shields et al., 1982) and M. zeylanica (Kaul and Ansari, 1981), have Z chromosomes which correspond to those seen in Ramphastidae. In contrast, the $\mathrm{W}$ chromosome is small and telocentric in $M$. haemacephala, and larger than the second pair of autosomes in M. zeylanica. Among the species of Ramphas- tidae examined here, the size and morphology of the sex chromosomes was less variable.

A comparative chromosome analysis of a great number of Ramphastidae species and of other families of the same order would improve the interpretation of chromosomal evolution in this group. Combining cytogenetic data with biogeography, phenotypic characteristics, DNA hybridization, and other approaches should provide a better understanding of the phylogenetic relationships in the avian family Ramphastidae.

\section{Acknowledgments}

The authors thank the curators of: Parques Ecológicos (Ecologic Parks) of Paulínia, Americana, Leme, Boituva, Ibirapuera and Tietê; Parques Zoológicos (Zoologic Gardens) of Bauru, Sorocaba and São Paulo; "Bosque dos Jequitibás" of Campinas; "Fazenda Crisciumal" farm of Leme; and "Criadouros Conservacionistas" (Conservative Breeders) of Souzas, Itupeva and Pirassununga, for putting their specimens at our disposal, and Dr. Edmundo J. De Lucca (Dept. of Genetics, Institute of Biology, UNESP, Botucatu, Brazil) for critical reading of the manuscript. This work was supported by CAPES and FAPESP.

\section{References}

Belterman RHR and De Boer LEM (1984) A karyological study of 55 species of birds, including karyotypes of 39 species new to cytology. Genetica 65:39-82.

Gould J (1992) Family of toucans: a monograph of the Ramphastidae. Jari, Companhia Florestal Monte Dourado, Belém - PA.

Kaul D and Ansari A (1981) Chromosomal polymorphism in a natural population of the northern green barbet, Megalaima zeylanica caniceps (Franklin) (Piciformes: Aves). Genetica 54:241-245.

Levan A, Fredga K and Sandberg AA (1964) Nomenclature for centromeric position of chromosomes. Hereditas 52:201-202.

Nogueira DM and Goldshimidt B (1995) Estudo cromossômico em Ramphastos toco. Braz. J. Genet. (suppl) 18:437. 41 Congresso Nacional de Genética, Caxambu, MG, Brazil.

Rodionov AV (1997) Evolution of avian chromosome and linkage groups. Genetica 33:725-738.

Shields GF, Jarrel GH and Redrupp E (1982) Enlarged sex chromosome of woodpeckers (Piciformes). The Auk 99:767-771.

Sibley CG (1996). Birds of the World (version 2.0), Thayer Birding Software.

Sick H (1997) Ornitologia Brasileira, uma Introdução. Nova Fronteira, Rio de Janeiro, $827 \mathrm{pp}$.

Takagi N and Sasaki M (1980) Unexpected karyotypical resemblance between the burmeister's seriema, Chunga burmeisteri (Gruiformes: Cariamidae) and the toucan, Ramphastos toco (Piciformes: Rhamphastidae). Chrom. Inf. Serv. 28:10-11. 